\title{
Thiosemicarbazone complexes of the platinum metals. A story of variable coordination modes
}

\author{
INDRANI PAL, FALGUNI BASULI and SAMARESH BHATTACHARYA* \\ Department of Chemistry, Inorganic Chemistry Section, Jadavpur University, \\ Kolkata 700 032, India \\ e-mail: samaresh_b@hotmail.com
}

\begin{abstract}
Salicylaldehyde thiosemicarbazone $\left(\mathrm{H}_{2} \mathrm{saltsc}\right)$ reacts with $\left[\mathrm{M}\left(\mathrm{PPh}_{3}\right)_{3} \mathrm{X}_{2}\right]$ $(\mathrm{M}=\mathrm{Ru}, \mathrm{Os} ; \mathrm{X}=\mathrm{Cl}, \mathrm{Br})$ to afford complexes of type $\left[\mathrm{M}\left(\mathrm{PPh}_{3}\right)_{2}(\mathrm{Hsaltsc})_{2}\right]$, in which the salicylaldehyde thiosemicarbazone ligand is coordinated to the metal as a bidentate N,S-donor forming a four-membered chelate ring. Reaction of benzaldehyde thiosemicarbazones (Hbztsc-R) with $\left[\mathrm{M}\left(\mathrm{PPh}_{3}\right)_{3} \mathrm{X}_{2}\right]$ also affords complexes of similar type, viz. $\left[\mathrm{M}\left(\mathrm{PPh}_{3}\right)_{2}(\text { bztsc- } \mathrm{R})_{2}\right]$, in which the benzaldehyde thiosemicarbazones have also been found to coordinate the metal as a bidentate N,S-donor forming a fourmembered chelate ring as before. Reaction of the Hbztsc-R ligands has also been carried out with $\left[\mathrm{M}(\mathrm{bpy})_{2} \mathrm{X}_{2}\right](\mathrm{M}=\mathrm{Ru}, \mathrm{Os} ; \mathrm{X}=\mathrm{Cl}, \mathrm{Br})$, which has afforded complexes of type $\left[\mathrm{M}(\text { bpy })_{2}(\text { bztsc-R })\right]^{+}$, which have been isolated as perchlorate salts. Coordination mode of bztsc-R has been found to be the same as before. Structure of the Hbztsc-OMe ligand has been determined and some molecular modelling studies have been carried out determine the reason for the observed mode of coordination. Reaction of acetone thiosemicarbazone (Hactsc) has then been carried out with $\left[\mathrm{M}(\mathrm{bpy})_{2} \mathrm{X}_{2}\right]$ to afford the $\left[\mathrm{M}(\mathrm{bpy})_{2}(\mathrm{actsc})\right] \mathrm{ClO}_{4}$ complexes, in which the actsc ligand coordinates the metal as a bidentate $\mathrm{N}, \mathrm{S}$-donor forming a five-membered chelate ring. Reaction of $\mathrm{H}_{2}$ saltsc has been carried out with $\left[\mathrm{Ru}(\mathrm{bpy})_{2} \mathrm{Cl}_{2}\right]$ to prepare the $\left[\mathrm{Ru}(\mathrm{bpy})_{2}(\mathrm{Hsaltsc})\right] \mathrm{ClO}_{4}$ complex, which has then been reacted with one equivalent of nickel perchlorate to afford an octanuclear complex of type $\left[\left\{\mathrm{Ru}(\mathrm{bpy})_{2}\right.\right.$ (saltsc$\left.\mathrm{H}){ }_{4} \mathrm{Ni}_{4}\right]\left(\mathrm{ClO}_{4}\right)_{4}$.
\end{abstract}

Keywords. Thiosemicarbazone complexes; platinum metals; variable coordination; four-membered chelate rings; molecular modelling; five-membered chelate ring.

\section{Introduction}

The chemistry of transition metal complexes of thiosemicarbazones has been receiving considerable attention largely because of their pharmacological properties. In the solid state, these thiosemicarbazones exist in the thione form (1). In solution, however, they are known to tautomerize into the thiol form (2). Complexation usually takes place via dissociation of the acidic proton, resulting in the formation of a five-membered chelate ring (3). When an additional donor site D is incorporated in such ligands, linked to the carbonylic carbon via one or two intervening atoms, D,N,S tricoordination usually takes place. With this knowledge taken from the literature ${ }^{1}$, we undertook the present study where thiosemicarbazones of different types have been used to interact with the platinum metals, ruthenium and osmium in particular. The resulting complexes have been observed

\footnotetext{
*For correspondence
} 
1<smiles>CC(C)=NNC(N)=S</smiles>

3<smiles>[M]C(C)=NN=C(N)O</smiles><smiles>C=CC</smiles>

4

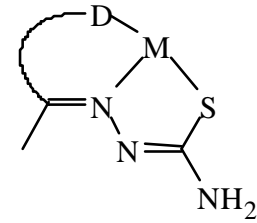

to display many interesting properties ${ }^{1-4}$. However, this present discussion is focused on a single aspect - namely the coordination of the thiosemicarbazone ligands, which, as we have experienced, is very unpredictable and hence quite interesting.

\section{Result and discussion}

Salicylaldehyde thiosemicarbazone (5, abbreviated as $\mathrm{H}_{2}$ saltsc where $\mathrm{H}_{2}$ stands for the two dissociable protons), was first used in our study with the expectation that it would bind to the metal ion as a tridentate O,N,S-donor (6). Reaction of $\mathrm{H}_{2}$ saltsc was first carried out with $\left[\mathrm{Ru}\left(\mathrm{PPh}_{3}\right)_{3} \mathrm{Cl}_{2}\right]$ in 1:2 molar ratio in the presence of $\mathrm{NEt}_{3}$, which afforded
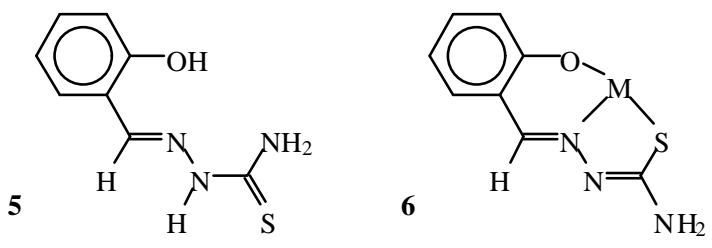

a bis-thiosemicarbazone complex, viz. $\left[\mathrm{Ru}\left(\mathrm{PPh}_{3}\right)_{2}(\mathrm{Hsaltsc})_{2}\right]$, in decent yield as below.

$$
\begin{aligned}
{\left[\mathrm{Ru}\left(\mathrm{PPh}_{3}\right)_{3} \mathrm{Cl}_{2}\right]+\mathrm{H}_{2} \text { saltsc } } & \underset{\text { stirred for } 30 \mathrm{~min},}{\text { room temp }(298 \mathrm{~K})}
\end{aligned}\left[\mathrm{Ru}\left(\mathrm{PPh}_{3}\right)_{2}(\mathrm{Hsaltsc})_{2}\right]
$$

The analogous osmium complex, viz. $\left[\mathrm{Os}\left(\mathrm{PPh}_{3}\right)_{2}(\mathrm{Hsaltsc})_{2}\right]$, was also synthesized starting from $\left[\mathrm{Os}\left(\mathrm{PPh}_{3}\right)_{3} \mathrm{Br}_{2}\right]$ by following a slightly different synthetic procedure as below.

$$
\left[\mathrm{Os}\left(\mathrm{PPh}_{3}\right)_{3} \mathrm{Br}_{2}\right]+\mathrm{H}_{2} \mathrm{saltsc} \underset{\text { stirred for } 2 \mathrm{~h}, 333 \mathrm{~K}}{\mathrm{NEt}} \text {, EtOH }\left[\mathrm{Os}\left(\mathrm{PPh}_{3}\right)_{2}(\text { Hsaltsc })_{2}\right]
$$




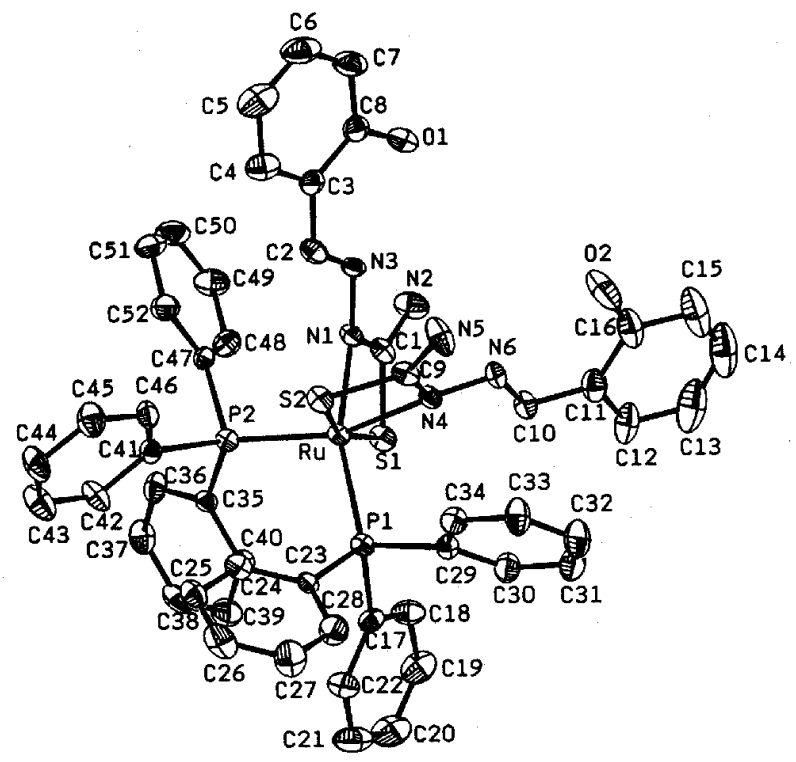

Figure 1. Structure of the $\left[\mathrm{Ru}\left(\mathrm{PPh}_{3}\right)_{2}(\mathrm{Hsaltsc})_{2}\right]$ complex.

From the preliminary characterization data it was evident that the thiosemicarbazone ligand serves as a monoanionic bidentate ligand, but the coordination mode of the thiosemicarbazone ligand was not clear. To determine the coordination mode of the thiosemicarbazone ligand, as well as the stereochemistry of the complexes, structure of the $\left[\mathrm{Ru}\left(\mathrm{PPh}_{3}\right)_{2}(\mathrm{Hsaltsc})_{2}\right]$ complex was determined by $\mathrm{X}$-ray crystallography. The structure (figure 1) shows that instead of having the phenolate oxygen as a potential donor site, the salicylaldehyde thiosemicarbazone ligands are coordinated to the metal as bidentate N,S-donors forming an unusual four-membered chelate ring (7). The two $\mathrm{PPh}_{3}$ ligands are mutually cis. The $\mathrm{N}_{2} \mathrm{P}_{2} \mathrm{~S}_{2}$ coordination sphere around the metal is significantly distorted from ideal octahedral geometry.<smiles>[M]C1SC(N)=NN1N=Cc1ccccc1O</smiles>

The observed coordination mode of the salicylaldehyde thiosemicarbazone (7) was rather unusual and initially it appeared that two factors might be responsible for such coordination: (i) the intramolecular hydrogen bonding between the phenolic hydrogen and the imine nitrogen, which probably made these two donor atoms unavailable for coordination, and (ii) the steric bulk of the $\mathrm{PPh}_{3}$ ligands which could prevent the thiosemicarbazone ligands to fold around the metal ion in a manner necessary for the O,N,S-tricoordination. We planned to find out the actual reason behind such a 
coordination mode (7) by following the method of elimination. In order to do that, first the $\mathrm{PPh}_{3}$ ligand was kept unchanged while the possibility of intramolecular hydrogen bonding was eliminated by removing the phenolic $-\mathrm{OH}$ group from the thiosemicarbazone ligand and three para-substituted benzaldehyde thiosemicarbazones (8) were used. The ligands are abbreviated in general as Hbztsc-R, where $\mathrm{H}$ stands for the dissociable proton and $\mathrm{R}$ for the substituent. This time our expectation was that these ligands would bind to the metal ions as bidentate $\mathrm{N}, \mathrm{S}$-donors forming five-membered chelate rings (9). Reactions of these Hbztsc-R ligands (8) were again carried out with
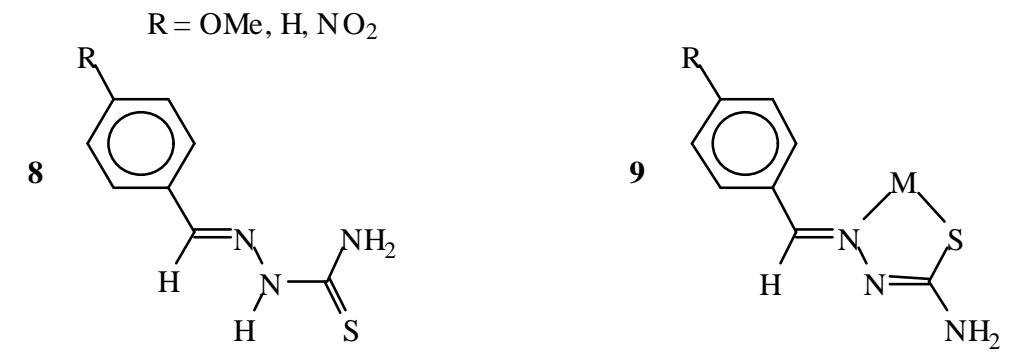

$\left[\mathrm{M}\left(\mathrm{PPh}_{3}\right)_{3} \mathrm{X}_{2}\right] \quad(\mathrm{M}=\mathrm{Ru}, \mathrm{Os} ; \mathrm{X}=\mathrm{Cl}, \mathrm{Br})$ and this time also bis thiosemicarbazone complexes of similar type, viz. $\left[\mathrm{M}\left(\mathrm{PPh}_{3}\right)_{2}(\text { bztsc-R })_{2}\right]$ were obtained as below.

$$
\begin{aligned}
& {\left[\mathrm{Ru}\left(\mathrm{PPh}_{3}\right)_{3} \mathrm{Cl}_{2}\right]+\text { Hbztsc-R } \underset{\text { refluxed for } 1 \mathrm{~h}}{\mathrm{NEt}_{3}, \mathrm{EtOH}} \rightarrow\left[\mathrm{Ru}\left(\mathrm{PPh}_{3}\right)_{2}(\text { bztsc-R })\right]_{2},} \\
& \left.\left[\mathrm{Os}\left(\mathrm{PPh}_{3}\right)_{3} \mathrm{Br}_{2}\right]+\text { Hbztsc-R } \underset{\begin{array}{c}
\text { refluxed for } 2 \mathrm{~h}\left(\mathrm{R}=\mathrm{NO}_{2}\right) \\
\text { stirred for } 3 \mathrm{~h}(\mathrm{R}=\mathrm{OMe}, \mathrm{H})
\end{array}}{\stackrel{\mathrm{NEt}_{3}, \mathrm{EtOH}}{\longrightarrow}}\left[\mathrm{PPh}_{3}\right)_{2}(\text { bztsc-R })\right]_{2} .
\end{aligned}
$$

Structure determination of the $\left[\mathrm{Ru}\left(\mathrm{PPh}_{3}\right)_{2}\left(\text { bztsc-NO } \mathrm{N}_{2}\right)_{2}\right]$ complex (figure 2) shows that the thiosemicarbazone ligands are again coordinated in a similar fashion (10) as before, forming four-membered chelate rings. This exercise therefore indicates that intramolecular hydrogen bonding is not responsible for the unusual coordination mode (7) observed in the case of the salicylaldehyde thiosemicarbazone complexes.

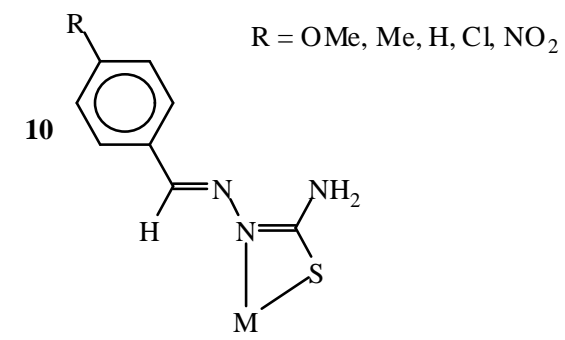

11<smiles>[R]c1ccc(/C=N/NC(N)=S)cc1</smiles> 


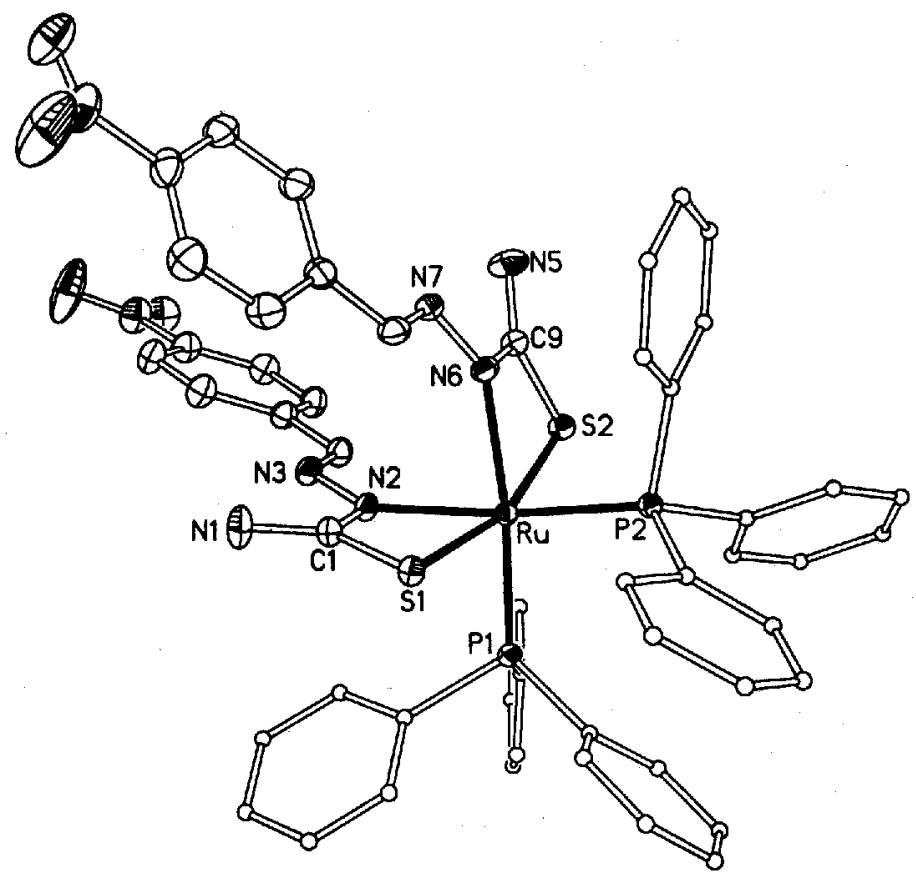

Figure 2. Structure of the $\left[\mathrm{Ru}\left(\mathrm{PPh}_{3}\right)_{2}\left(\text { bztsc- }-\mathrm{NO}_{2}\right)_{2}\right]$ complex.

Prompted by the above results, we next planned to reduce the volume of the coligand to avoid any possible steric interaction and selected 2,2'-bipyridine (bpy) instead of $\mathrm{PPh}_{3}$. Reactions of five para-substituted benzaldehyde thiosemicarbazones (11) were carried out as below with both $\left[\mathrm{Ru}(\mathrm{bpy})_{2} \mathrm{Cl}_{2}\right]$ and $\left[\mathrm{Os}(\mathrm{bpy})_{2} \mathrm{Br}_{2}\right]$ to afford mixed ligand complexes of type $\left[\mathrm{M}(\mathrm{bpy})_{2}(\mathrm{bztsc}-\mathrm{R})\right]^{+}$, which were isolated as perchlorate salts.

$$
\begin{aligned}
{\left[\mathrm{Ru}(\mathrm{bpy})_{2} \mathrm{Cl}_{2}\right] } & \stackrel{\mathrm{Ag}^{+}}{\mathrm{EtOH}}\left[\mathrm{Ru}(\mathrm{bpy})_{2}(\mathrm{EtOH})_{2}\right]^{2+} \\
& \frac{\mathrm{Hbztsc}-\mathrm{R}, \mathrm{NEt}_{3}}{\text { refluxed for } 2 \mathrm{~h}, \mathrm{NaClO}_{4}} \rightarrow\left[\mathrm{Ru}(\mathrm{bpy})_{2}(\text { bztsc-R })\right] \mathrm{ClO}_{4}, \\
{\left[\mathrm{Os}(\mathrm{bpy})_{2} \mathrm{Br}_{2}\right]+} & \mathrm{Hbztsc- \textrm {R }} \\
& \stackrel{\mathrm{NEt}_{3}, \mathrm{EtOH}-\mathrm{H}_{2} \mathrm{O}}{\text { refluxed for } 6 \mathrm{~h}, \mathrm{NaClO}_{4}} \rightarrow\left[\mathrm{Os}(\mathrm{bpy})_{2}(\text { bztsc-R })\right] \mathrm{ClO}_{4} .
\end{aligned}
$$

To determine the coordination mode of the thiosemicarbazone ligands in these complexes, the structure of a representative member of this family, viz. $\left[\mathrm{Ru}(\mathrm{bpy})_{2}\right.$ (bztsc$\left.\mathrm{NO}_{2}\right)^{+}$, was determined. The structure (figure 3) shows that the thiosemicarbazone ligand 


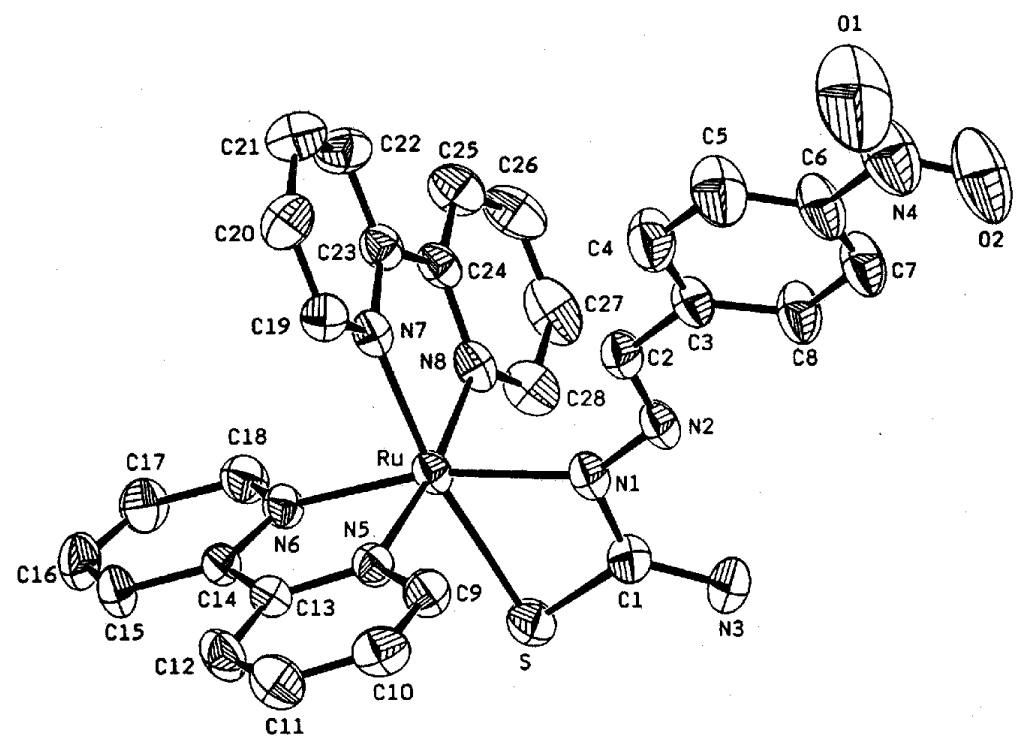

Figure 3. Structure of the $\left[\mathrm{Ru}(\mathrm{bpy})_{2}\left(\mathrm{bztsc}-\mathrm{NO}_{2}\right)\right]^{+}$complex.

is again coordinated to the metal in the same fashion (10) as before. Formation of fourmembered chelate ring by the bztsc-R ligands even after all these modifications (viz. removal of the $-\mathrm{OH}$ group from the salicylaldehyde thiosemicarbazone and replacement of $\mathrm{PPh}_{3}$ by less bulky bpy as coligand), clearly indicates that neither intramolecular hydrogen bonding nor steric interaction of the thiosemicarbazone ligands with $\mathrm{PPh}_{3}$ is the actual driving force behind the observed coordination mode. However, these modification exercises led us to the conclusion that the restrictions in five-membered ring formation (9) must be arising primarily from the thiosemicarbazone ligand itself. To determine the origin of such a four-membered ring formation, the stereochemistry of benzaldehyde thiosemicarbazone was first taken into consideration. Owing to the restricted rotation

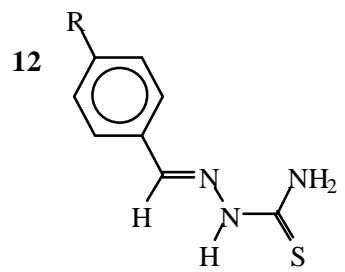

13<smiles>[R]c1ccc(/C=N\N([2H])C(N)S)cc1</smiles>

around the $\mathrm{C}=\mathrm{N}$ bond, the Hbztsc-R ligands may exist in two different geometric isomeric forms $(\mathbf{1 2}, \mathbf{1 3})$. The structure determination of one representative ligand, viz. Hbztsc-OMe, shows (figure 4) that the free ligand exists in thione form and corresponds to structure 12 where the aryl group is trans to the hydrazinic nitrogen across the $\mathrm{C}=\mathrm{N}$ bond. Starting from the free ligand, five-membered chelate ring formation (9) can take place, in principle, via rotation about the $\mathrm{C}-\mathrm{N}$ (hydrazinic) single bond, followed by 


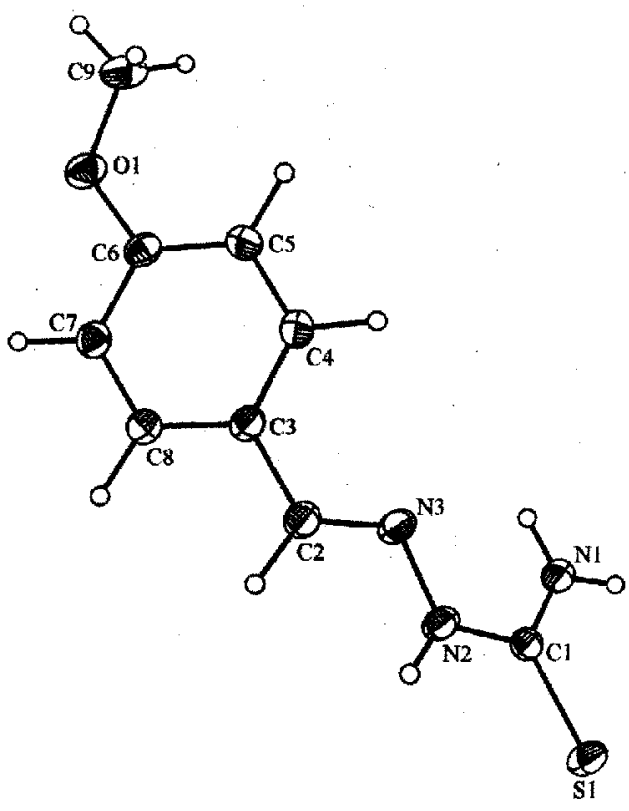

Figure 4. Structure of the Hbztsc-OMe ligand.<smiles>[R]c1ccc(/C=N/[Y19]([H])=S)cc1</smiles><smiles>[R]c1ccc(/C=N/NC(N)=S)cc1</smiles><smiles>[R]c1ccc(/C=N\N=C(/N)SCC)cc1</smiles><smiles>[M][In]C</smiles><smiles>[R]c1ccc(/C=N\N=C(/N)S)cc1</smiles>

Scheme 1. Probable steps involved in the formation of five-membered chelate rings.

tautomerization to the thiol form and dissociation of the thiolate proton upon complexation (scheme 1). To get an idea about the possible restrictions in forming such five-membered ring (9), a computer model of $\left[\mathrm{Ru}(\mathrm{bpy})_{2}(\mathrm{bztsc}-\mathrm{H})\right]^{+}$was constructed, forcing five-membered chelate ring formation by the thiosemicarbazone ligand. These modelling studies show that in this coordination mode, the phenyl ring of the thiosemicarbazone ligand comes in contact with the metal and also with the pyridine ring (of one bpy) trans to the thiolate sulphfur (figure 5). Hence such a coordination mode 
appears to be impossible for the benzaldehyde thiosemicarbazone. This exercise thus clearly indicates that (see scheme 2) (i) four-membered chelate ring formation is the most usual mode of coordination for the benzaldehyde thiosemicarbazones, as it does not involve any change in ligand geometry and does not pose any steric problem, (ii) fivemembered chelate ring formation by the benzaldehyde thiosemicarbazone is possible only if the aryl ring and the azomethine proton exchange places, which involves restricted rotation around the $\mathrm{C}=\mathrm{N}$ bond and hence such a coordination mode is quite unexpected, and (iii) five-membered ring formation by benzaldehyde thiosemicarbazone, keeping the geometry of the ligand intact across the $\mathrm{C}=\mathrm{N}$ bond, is impossible because of the steric interaction between the aryl rings and metal. The difficulty in forming five-membered chelate rings by benzaldehyde thiosemicarbazone therefore is due to the combined effect of restricted rotation about the $\mathrm{C}=\mathrm{N}$ bond and steric bulk of the aryl group. Now restriction in rotation about the $\mathrm{C}=\mathrm{N}$ bond is an intrinsic property of such a bond, which is hard to overcome. However, the size of the aryl group, creating the steric problem, can be reduced easily by changing the group and our modelling study indicates that if the bulk of this group can be reduced to such an extent that it would no longer come in contact with the metal as well as the coligands, five-membered ring formation should be possible. Hence we planned to use acetone thiosemicarbazone (Hactsc, 14) instead of benzaldehyde thiosemicarbazone. Before carrying out the actual synthetic reactions, a modelling study was performed on one target complex, viz. $\left[\mathrm{Ru}(\mathrm{bpy})_{2}(\mathrm{actsc})\right]^{+}$. This time our studies show that there is no steric problem in forming five-membered rings by actsc ligand (figure 6). Encouraged by this result, we prepared the $\left[\mathrm{M}(\mathrm{bpy})_{2}(\mathrm{actsc})\right]^{+}(\mathrm{M}=\mathrm{Ru}$, Os) complexes below, isolated as perchlorate salts.<smiles>CC(C)=NNC(N)=S</smiles>

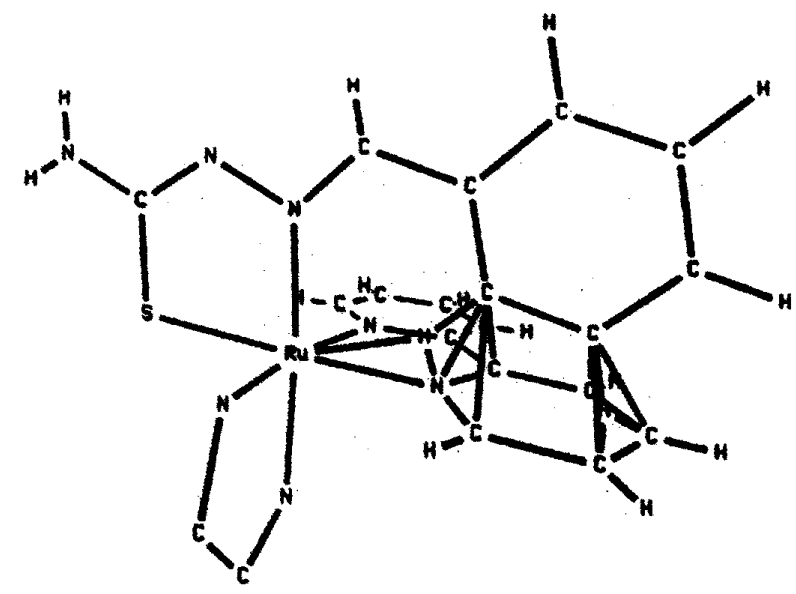

Figure 5. Steric interaction in $\left[\mathrm{Ru}(\mathrm{bpy})_{2}(\mathrm{bztsc}-\mathrm{H})\right]^{+}$. The ring carbons of one bpy have been omitted for clarity. 


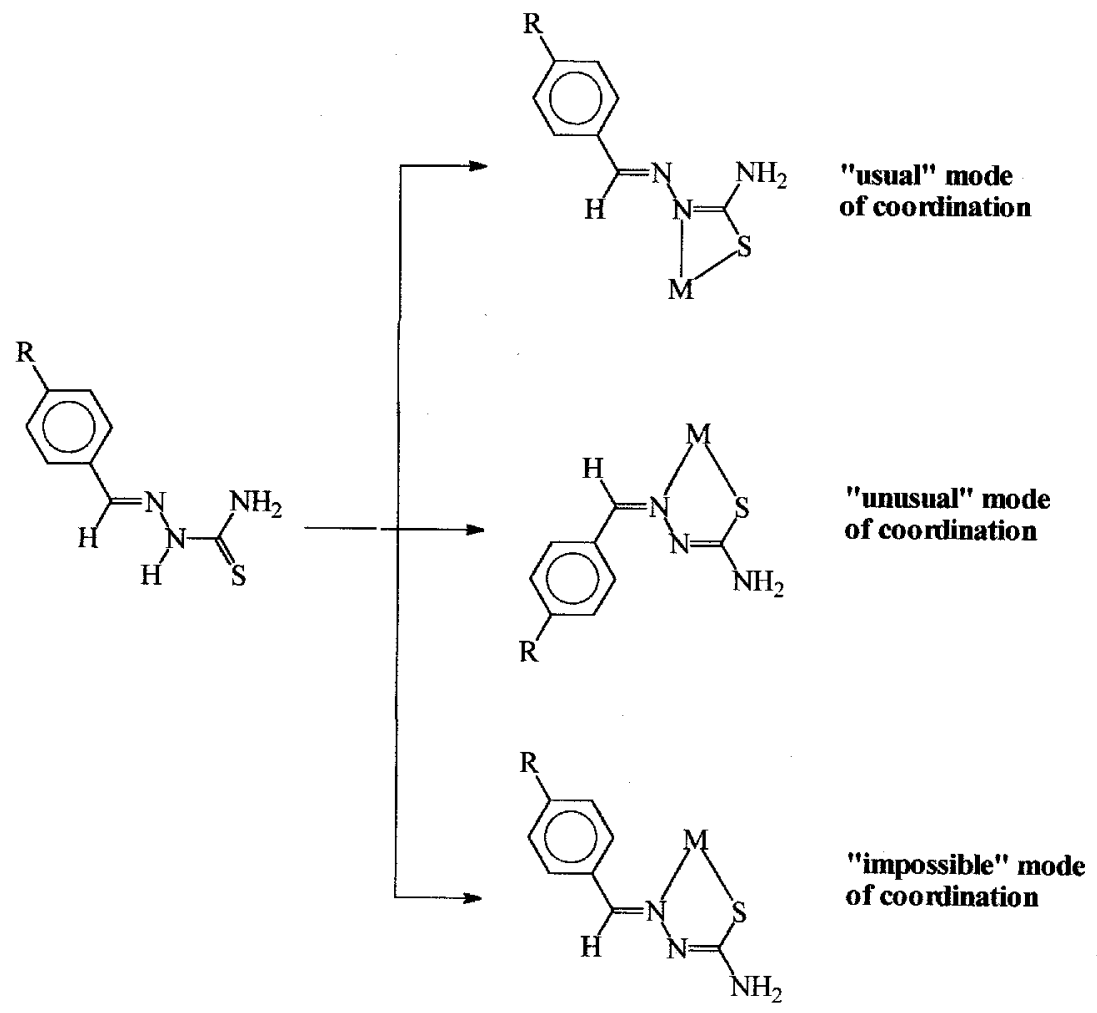

Scheme 2. Results of the modelling studies on the $\left[\mathrm{M}(\mathrm{bpy})_{2}(\mathrm{bztsc}-\mathrm{R})\right]^{+}$complexes.

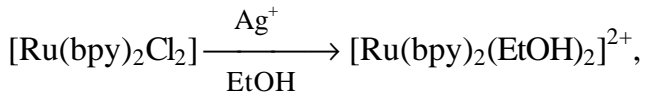

$$
\begin{aligned}
& \text { Hactsc, } \mathrm{NEt}_{3} \\
& \underset{\text { refluxed for } 2 \mathrm{~h}, \mathrm{NaClO}_{4}}{\longrightarrow}\left[\mathrm{Ru}(\text { bpy })_{2}(\text { actsc })\right] \mathrm{ClO}_{4} \text {, } \\
& {\left[\mathrm{Os}(\mathrm{bpy})_{2} \mathrm{Br}_{2}\right]+\mathrm{Hbztsc}} \\
& \frac{\mathrm{NEt}_{3}, \mathrm{EtoH}-\mathrm{H}_{2} \mathrm{O}}{\text { refluxed for } 6 \mathrm{~h}, \mathrm{NaClO}_{4}} \rightarrow\left[\mathrm{Os}(\mathrm{bpy})_{2}(\text { actsc })\right] \mathrm{ClO}_{4} \text {. }
\end{aligned}
$$

Structure determination of the ruthenium complex (figure 7) shows that the acetone thiosemicarbazone ligand is indeed coordinated to the metal as a bidentate N,S-donor forming a five-membered chelate ring. The conclusion arrived at from the above studies so far is illustrated in scheme 3. The steric bulk of the alkyl/aryl group (R) plays the key role in dictating the coordination mode of the thiosemicarbazone ligands. When $\mathrm{R}$ is large, four-membered chelate ring formation is most expected and five-membered ring formation (involving restricted rotation around the $\mathrm{C}=\mathrm{N}$ bond) is rather unexpected. 


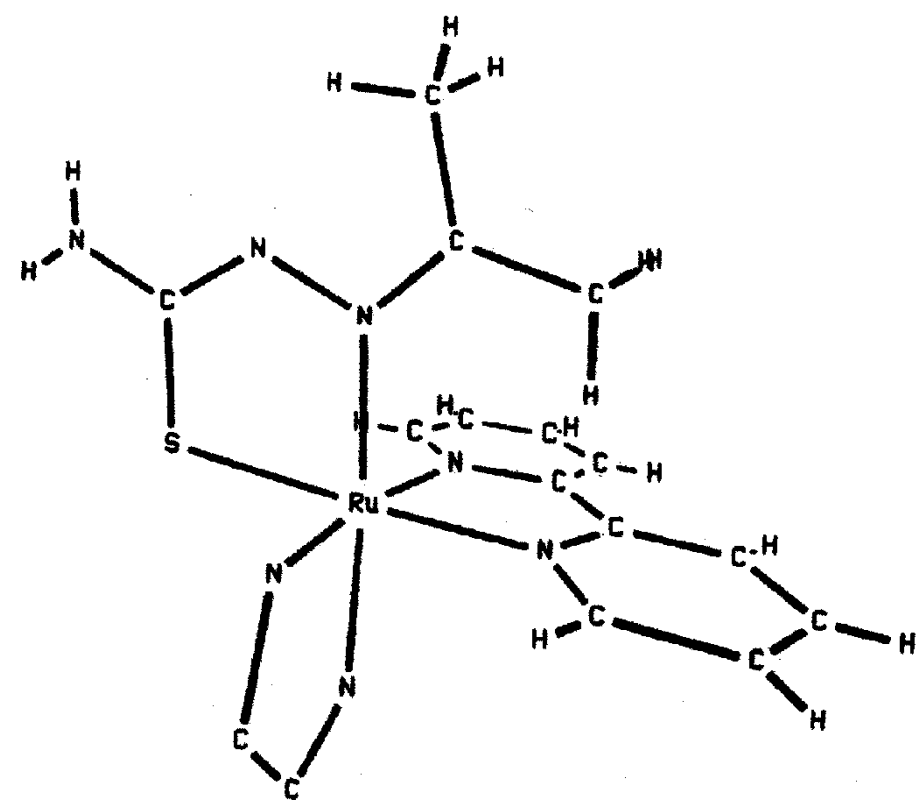

Figure 6. Steric interaction in $\left[\mathrm{Ru}(\mathrm{bpy})_{2}(\mathrm{actsc})\right]^{+}$. The ring carbons of one bpy have been omitted for clarity.

However, when $\mathrm{R}$ is small, five-membered ring formation (without involving any rotation around the $\mathrm{C}=\mathrm{N}$ bond) is always possible.

A careful look at the coordination mode displayed by the salicylaldehyde thiosemicarbazone in its reaction with ruthenium and osmium (7) reveals that in spite of having five potential donor sites (three $\mathrm{N}$, one $\mathrm{O}$ and one $\mathrm{S}$ atom), this ligand has utilized only two donor sites (one $\mathrm{N}$ and one $\mathrm{S}$ atom), while the other three potential donor sites (viz. the phenolate oxygen, the imine nitrogen and the amine nitrogen) have remained unutilized. The relative dispositions in space of these three unused donor sites in 7 suggest that complexes containing this moiety (7) should be able to bind to a second metal ion as a tridentate N,N,O-donor ligand (15). In order to explore such a possibility,

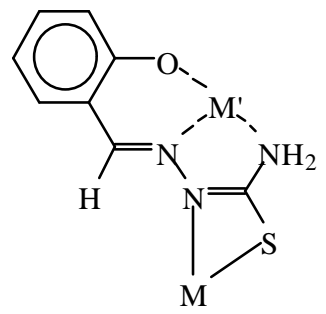

first a mixed ligand salicylaldehyde thiosemicarbazone complex of ruthenium, viz. $\left[\mathrm{Ru}(\mathrm{bpy})_{2}(\mathrm{Hsaltsc})\right] \mathrm{ClO}_{4}$, was prepared as below. 


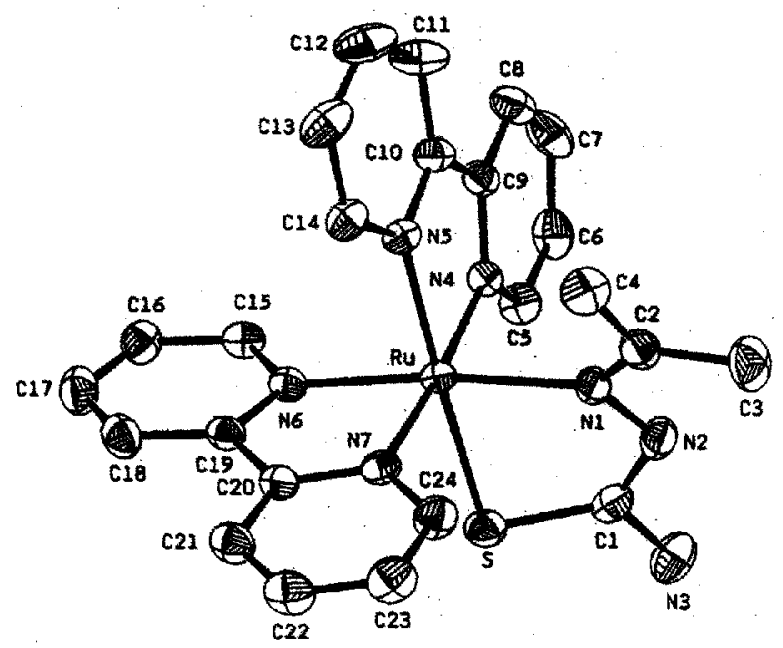

Figure 7. Structure of the $\left[\mathrm{Ru}(\mathrm{bpy})_{2}(\operatorname{actsc})\right]^{+}$complex.

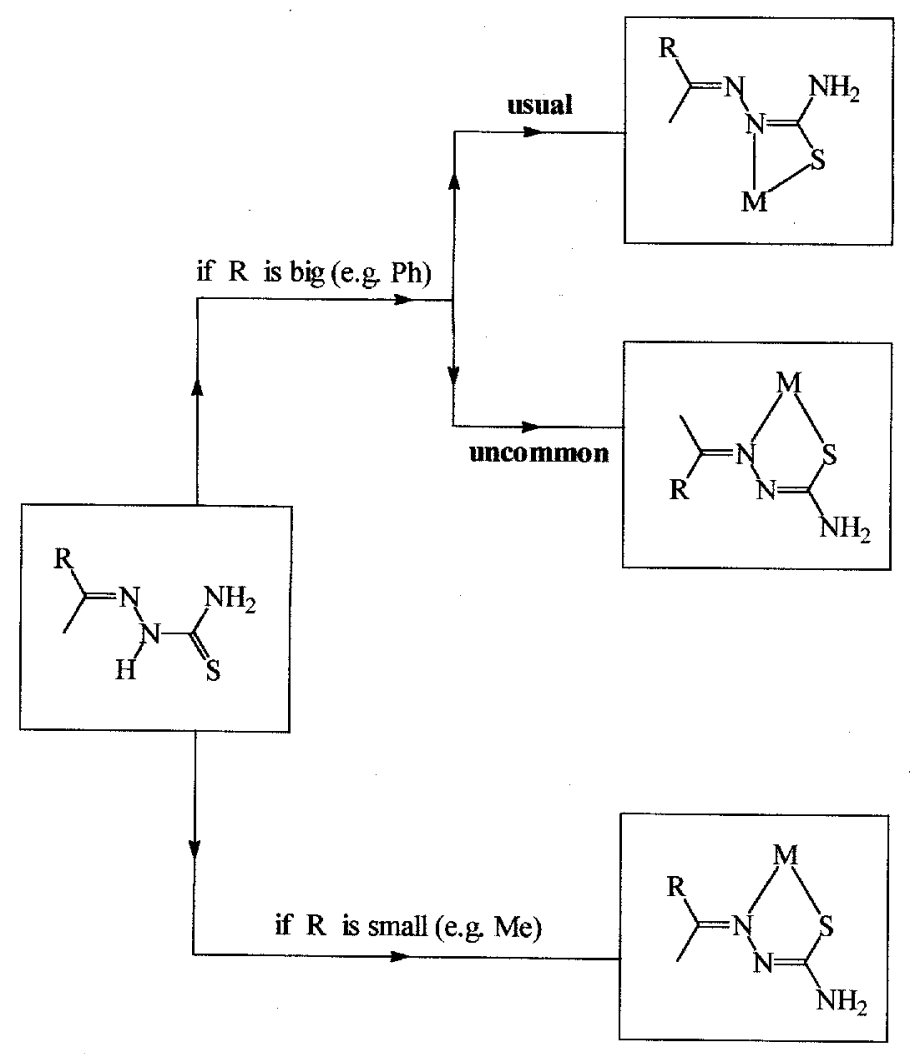

Scheme 3. Conclusions arrived at after all the modification exercises. 


$$
\begin{aligned}
{\left[\mathrm{Ru}(\mathrm{bpy})_{2} \mathrm{Cl}_{2}\right] \underset{\mathrm{EtOH}}{\stackrel{\mathrm{Ag}^{+}}{\longrightarrow}\left[\mathrm{Ru}(\mathrm{bpy})_{2}(\mathrm{EtOH})_{2}\right]^{2+},} } \\
\qquad \underset{\mathrm{H}_{2} \text { saltsc, } \mathrm{NEt}_{3}}{\stackrel{\text { refluxed for } 2 \mathrm{~h}, \mathrm{NaClO}_{4}}{\longrightarrow}}\left[\mathrm{Ru}(\mathrm{bpy})_{2}(\text { Hsaltsc })\right] \mathrm{ClO}_{4} .
\end{aligned}
$$

Structure determination of this complex shows (figure 8) that the Hsaltsc ligand is coordinated to ruthenium as before (7) leaving three donor sites unutilized. To test the efficiency of this complex as a tridentate ligand, its reaction was then carried out with one equivalent of $\mathrm{Ni}\left(\mathrm{ClO}_{4}\right)_{2} \cdot 6 \mathrm{H}_{2} \mathrm{O}$, which actually afforded a polynuclear complex, viz. $\left[\left\{\mathrm{Ru}(\text { bpy })_{2}(\text { saltsc-H })\right\}_{4} \mathrm{Ni}_{4}\right]^{4+}$, isolated as the perchlorate salt. Structure determination on

$$
\left[\mathrm{Ru}(\text { bpy })_{2}(\mathrm{Hsaltsc})\right] \mathrm{Cl}_{4} \underset{\begin{array}{c}
\text { EtOH-acetonitrile, } \\
\text { warmed, stirred for } 5 \mathrm{~h}
\end{array}}{\stackrel{\mathrm{NEt}_{3}, \mathrm{Ni}\left(\mathrm{ClO}_{4}\right)_{2} 6 \mathrm{H}_{2} \mathrm{O}}{\longrightarrow}}\left[\left\{\mathrm{Ru}(\mathrm{bpy})_{2}(\text { saltsc-H })\right\}_{4} \mathrm{Ni}_{4}\right]\left(\mathrm{ClO}_{4}\right)_{4} \text {. }
$$

this complex shows (figure 9) that the coordinated Hsaltsc ligand of $\left[\mathrm{Ru}(\mathrm{bpy})_{2}(\mathrm{Hsaltsc})\right]^{+}$ has lost two more protons, viz. the phenolic proton and one proton from the $\mathrm{NH}_{2}$ group, and is coordinated to nickel as a tridentate N,N,O-donor. The fourth coordination site of nickel is occupied by the sulphur atom of another $\left\{\mathrm{Ru}(\mathrm{bpy})_{2}(\right.$ saltsc-H) $\} \mathrm{Ni}$ fragment and it is this bridging action of sulphur which has resulted in the formation of the octanuclear

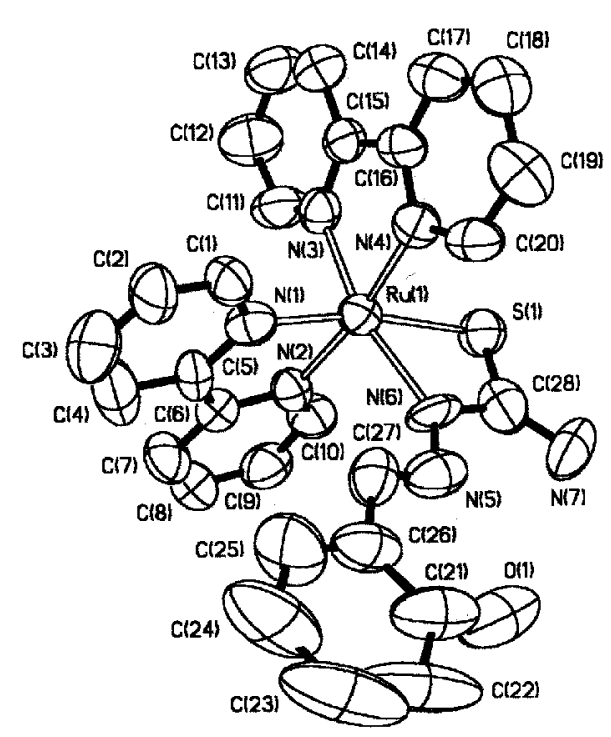

Figure 8. Structure of the $\left[\mathrm{Ru}(\mathrm{bpy})_{2}(\text { Hsaltsc })\right]^{+}$complex. 


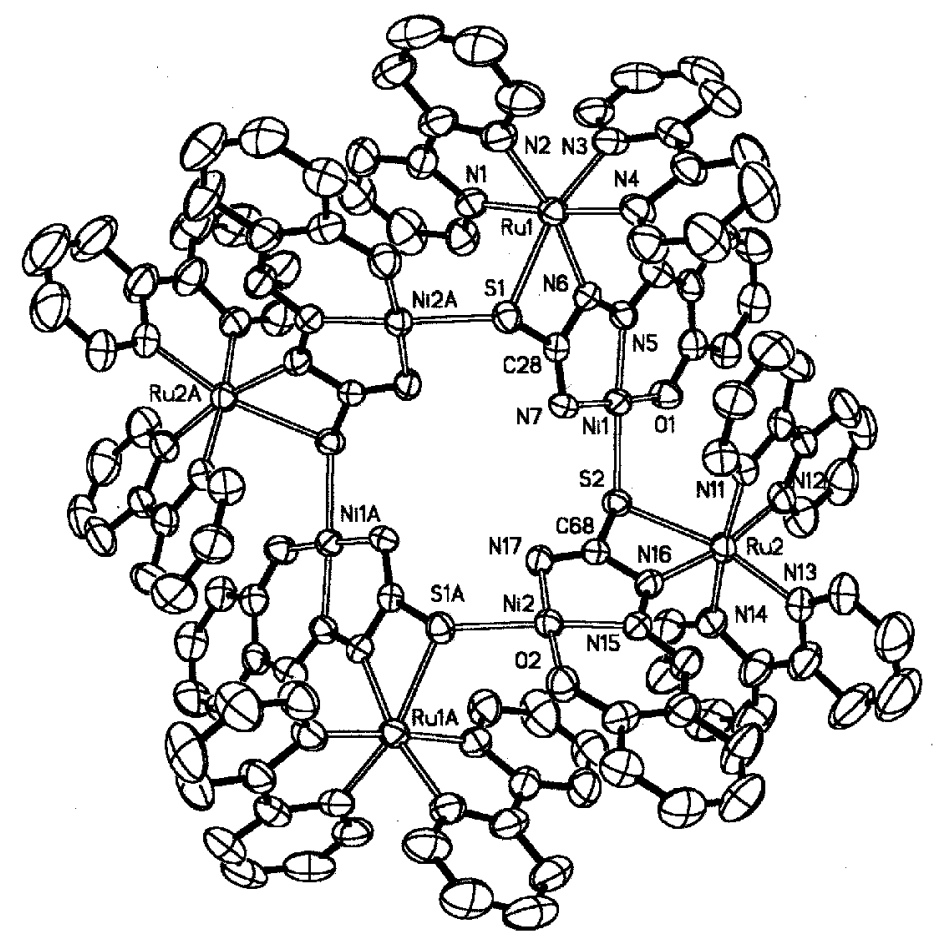

Figure 9. Structure of the $\left[\left\{\mathrm{Ru}(\mathrm{bpy})_{2}(\text { saltsc-H })\right\}_{4} \mathrm{Ni}_{4}\right]^{4+}$ complex.

complex. It is interesting to note that in this octanuclear complex, all the available donor sites of the salicylaldehyde thiosemicarbazone ligand are engaged in coordination, and such a coordination mode with this ligand is unprecedented in the literature.

\section{Conclusions}

The present study reveals that many interesting coordination modes are possible for the thiosemicarbazone ligands and the mode of coordination primarily depends on the properties of the alkyl/aryl group, which is trans to the hydrazinic nitrogen across the $\mathrm{C}=\mathrm{N}$ bond.

\section{Acknowledgements}

Our sincere thanks are due to Prof A Chakravorty (Indian Association for the Cultivation of Science, Kolkata), Prof S M Peng (National Taiwan University, ROC), Prof CG Pierpont and Dr M Ruf (University of Colorado at Boulder, USA) and Prof T C W Mak (Chinese University of Hong Kong), for their kind help in solving the crystal structures. Financial assistance received from the Department of Science and Technology, New Delhi and the Council of Scientific and Industrial Research, New Delhi, is gratefully acknowledged. 


\section{References}

1. Basuli F, Peng S M and Bhattacharya S 1997 Inorg. Chem. 36 5645, and references cited therein 2. Basuli F, Ruf M, Pierpont C G and Bhattacharya S 1998 Inorg. Chem. 376113

3. Basuli F, Peng S M and Bhattacharya S 2000 Inorg. Chem. 391120

4. Pal I, Basuli F, Mak T C W and Bhattacharya S 2001 Angew. Chem., Int. Ed. Engl. 402923 